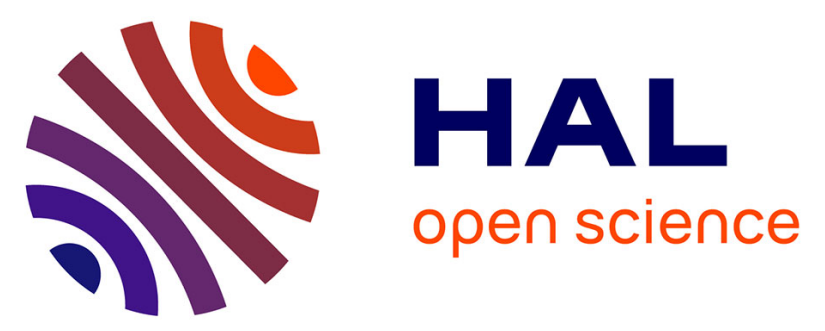

\title{
Effects of physical activity, body mass index, waist-to-hip ratio and waist circumference on total mortality risk in the Swedish National March Cohort
}

\author{
Rino Bellocco, Chongqi Jia, Weimin Ye, Ylva Trolle Lagerros
}

\section{To cite this version:}

Rino Bellocco, Chongqi Jia, Weimin Ye, Ylva Trolle Lagerros. Effects of physical activity, body mass index, waist-to-hip ratio and waist circumference on total mortality risk in the Swedish National March Cohort. European Journal of Epidemiology, 2010, 25 (11), pp.777-788. 10.1007/s10654-010-9497-6 . hal-00616293

\section{HAL Id: hal-00616293 \\ https://hal.science/hal-00616293}

Submitted on 22 Aug 2011

HAL is a multi-disciplinary open access archive for the deposit and dissemination of scientific research documents, whether they are published or not. The documents may come from teaching and research institutions in France or abroad, or from public or private research centers.
L'archive ouverte pluridisciplinaire HAL, est destinée au dépôt et à la diffusion de documents scientifiques de niveau recherche, publiés ou non, émanant des établissements d'enseignement et de recherche français ou étrangers, des laboratoires publics ou privés. 
Effects of physical activity, body mass index, waist-to-hip ratio and waist circumference on total mortality risk in the Swedish National March Cohort

\author{
Rino Bellocco ${ }^{1,2,}$ Chongqi Jia ${ }^{1,3}$, Weimin Ye $^{1}$, Ylva Trolle Lagerros ${ }^{4}$ \\ ${ }^{1}$ Department of Medical Epidemiology and Biostatistics, Karolinska Institutet, Sweden \\ ${ }^{2}$ Department of Statistics, University of Milano-Bicocca, Milan, Italy \\ ${ }^{3}$ Department of Epidemiology and Health Statistics, Shandong University, P.R.China \\ ${ }^{4}$ Department of Medicine, Unit of Clinical Epidemiology, Karolinska Institutet, Sweden
}

Correspondence to:

Ylva Trolle Lagerros

Department of Medicine, Unit of Clinical Epidemiology, Karolinska Institutet

Mailing address: T2, SE 171 76, Stockholm, Sweden

Telephone: +46-8-517 79183

Fax: +46-8-517 79304

Email: ylva.trolle@ki.se

**Rino Bellocco and Chongqi Jia equally share the first authorship

Running title: Physical activity, anthropometric measures and total mortality 


\section{Abbreviations:}

BMI = Body Mass Index

$\mathrm{CI}=$ Confidence Interval

HR = Hazard Ratio

ICD = International Classification of Disease

$\mathrm{IQR}=$ Interquartile Range

MET $=$ Metabolic Energy Turnover

$\mathrm{PA}=$ Physical Activity

$\mathrm{PAL}=$ Physical Activity Level

STEPPS $=$ Subpopulation Treatment Effect Pattern Plot

$\mathrm{WC}=$ Waist Circumference

WHR = Waist-to-Hip Ratio 


\begin{abstract}
The health benefits of physical activity (PA) have been well documented. However, there is less research investigating whether or not these health benefits might differ among males and females or among subjects characterized by different levels of body mass index (BMI), waist-to-hip ratio (WHR), and waist circumference (WC). Baseline total PA, BMI, WHR and waist circumference were measured in 14,585 men and 26,144 women who participated in the Swedish National March. Their effects on all-cause mortality were analyzed with a follow-up time of almost 10 years. Sedentary men with a BMI $\geq 30$ had an $80 \%$ (95\% CI: $19 \%-174 \%)$ increased risk of mortality compared to normal weight men with a high level of total PA. The same trend was observed for sedentary men with high WHR or waist circumference, compared to lean and highly active men. Sedentary women with a waist circumference of $88 \mathrm{~cm}$ or more had almost doubled, i.e. $97 \%(95 \%$ CI:35\%-189\%) increased mortality risk compared to physically active women with a waist circumference below $80 \mathrm{~cm}$. BMI in men, but waist circumference in women better forecast all-cause mortality. We found no substantial effect modification between different measures of adiposity and physical activity - physical inactivity and obesity seem to increase total mortality risk independently and additively.
\end{abstract}

Words: 209

Key Words: Body Mass Index; Cohort Studies; Epidemiology; Exercise; Mortality; Waist-Hip Ratio 


\section{Introduction}

Both physical inactivity and obesity have been recognized as important risk factors for major chronic diseases and premature mortality in most developed and developing countries [1]. The prevalence of physical inactivity and obesity is on a rapid increase and as a consequence has resulted in major public health problems worldwide [2, 3]. Epidemiological studies have shown an inconsistent relationship between body mass index (BMI) and mortality risk, with associations being J- or U-shaped [4-12], direct linear [13-16] or absent $[17,18]$. This could be due to the inadequate control for smoking status and pre-existing chronic diseases, both of which are associated with a low BMI and an increased risk of death [19]. One possible approach to control this bias is to disregard deaths occurring in the initial period of follow-up and to restrict the analyses to "never smokers', without pre-existing chronic diseases. Lately, even offspring BMI has been used as an indicator of BMI to avoid the risk of reverse causality when studying the association between BMI and mortality [20].

There are several methods to measure body fatness. The relative ease and low cost of obtaining BMI make it commonly used in epidemiological studies and routine clinical care. Nonetheless, it does not distinguish fat mass from lean body mass [19], nor does it capture the distribution of fat over the body [21]. With a high specificity of detecting obesity but a lower sensitivity, centralized obesity is not always captured by a high BMI alone [22]. Waist circumference or waist-to-hip ratio (WHR) may offer additional insights. Pischon et al. [23] showed that measurement of both general and centralized adiposity provides a better assessment of the risk of death - especially among those with a lower BMI. Other studies have shown that centralized adiposity as measured by WHR 
may be a more accurate predictor of cardiovascular risk than BMI [24], while waist circumference has been shown to independently predict risk of type II diabetes better than BMI and WHR [25].

A number of prospective studies [26-31] and reviews [32,33] demonstrate that physical activity could substantially decrease mortality. However, whether the health benefits of physical activity interact with well-known mortality risk factors, such as obesity, has not been studied extensively. It has been proposed that physical activity could counteract the risk of obesity. Physical activity has been shown to weaken, but not eliminate the heightened risk associated with excess weight $[15,34,35]$. However, many studies to date measure only one component of total activity, such as leisure time or occupational physical activity, which may not be a true representation of actual total physical activity.

In this prospective study, we used a validated nine-step instrument to assess total physical activity [36]. We focused on examining the inter- and intra-relationships between total physical activity, BMI, WHR, waist circumference and all-cause mortality in men and women in the Swedish National March Cohort.

\section{Subjects and Methods}

\section{Study cohort}

In September 1997 we targeted a general population cohort, the Swedish National March Cohort which has been described in detail previously [37]. The National March, was a four day national fund raising event arranged by the Swedish Cancer Society and taking place in almost 3,600 Swedish cities and villages. All National March participants were 
invited to fill out a 32-page questionnaire with detailed questions about energy intake, energy expenditure, anthropometric measures and conceivable confounders. It was assumed that participants would be particularly motivated to provide valid and high quality exposure information. Follow-up was facilitated by the provision of national registration numbers (unique identification numbers assigned to all Swedish residents), enabling accurate tracking of health status through linkage to existing nationwide and continuously updated databases.

Due to the character of this event, the total number of individuals who were actually given a questionnaire could not be assessed. In total 43,880 participants with a mean age of 50.3 years, (7.7 to 94.2 years old), completed the questionnaire, but we excluded subjects due to any type of cancer $(n=2,752)$, cardiovascular disease $(n=362$, ICD-10 codes: I00-I99), subjects with an incorrect national registration number $(n=12)$, death at time of enrollment $(n=8)$, subjects below the age of 20 years at the end of follow-up $(n=7)$, emigration at time of enrollment $(n=6)$ and clearly inconsistent answers $(n=4)$. Thus, there were 40,729 subjects included in the final analysis, 14,585 men and 26,144 women. The study was approved by the Regional Ethical Review Board at Karolinska Institutet and all subjects provided informed consent.

\section{Baseline measures}

Total physical activity was self-reported. In addition, participants were also requested to measure and report their height, weight, waist circumference (at the umbilicus) and hip circumference (maximal trochanters) - for the latter two, there was a pictured instruction in the questionnaire. 
Physical activity during an average week day was estimated using an instrument with nine physical activity steps which graded physical activity according to intensity. Each step was assigned a value expressed as a multiple of Metabolic Energy Turnover (MET) and exemplified by common activities. MET is defined as the ratio of work metabolic rate to a standard resting metabolic rate of $1 \mathrm{kcal} \cdot \mathrm{kg}^{-1}$ body weight $\cdot$ hour ${ }^{-1}$, with 1 MET equivalent to quiet sitting $[38,39]$. The MET values assigned to the nine different steps were $0.9,1.0,1.5,2.0,3.0,4.0,5.0,6.0$ and 8.0. Participants were instructed to report the time spent on each intensity level during an average day and night, hence total physical activity time should add up to 24 hours and allow for an estimate of MET $\bullet$ hours per day (METh/day) and a total physical activity score using the equation of $\sum_{i=1}^{9} t_{i} \cdot M E T_{i}$. This nine-step total physical activity instrument has been previously validated giving a Pearson correlation coefficient of 0.73 with three 24 -h recalls [36]. In a validation study with doubly labeled water as a reference, the mean difference in PAL (physical activity level, i.e. total energy expenditure minus basal metabolic rate) between the reference method and the instrument was small, 0.07 [40]. The physical activity questionnaire is available online [41].

The distribution of total physical activity was categorized into low, medium and high levels by dividing METh/day into tertiles, with cutoffs of 34.3 and $46.9 \mathrm{METh} /$ day for males and 31.5 and 38.9 METh/day for females, respectively. Waist circumference was categorized according to the International Diabetes Federation consensus defining central obesity in Europids as a waist circumference $\geq 94 \mathrm{~cm}$ and severe obesity to $\geq 102$ in men and $\geq 80$ respectively $\geq 88 \mathrm{~cm}$ in non-pregnant women [42]. BMI was calculated as weight 
in kilograms divided by height in meters squared and categorized as normal weight $(<25$ $\mathrm{kg} / \mathrm{m}^{2}$ ), overweight $\left(25-29.9 \mathrm{~kg} / \mathrm{m}^{2}\right)$ and obese $\left(\geq 30 \mathrm{~kg} / \mathrm{m}^{2}\right)$. Waist-hip ratio (WHR) was defined as the ratio of circumference of waist to hip; cut-offs were selected according to the clinical criteria for central obesity, 1.0 for men and 0.8 for women.

Among possible confounders we included cigarette smoking (never, past, current); alcohol drinking (all types of alcoholic beverage: never, low: $\leq 3$ times/month, medium: 1-6 time/week, high: $\geq 1$ time/day); use of vitamin and mineral supplements (no, yes) and level of education (7-9, 10-12 or >12 years), use of contraceptive pills (no, yes) and hormone replacement therapy (no, yes).

\section{Follow-up}

Follow-up started on October 1, 1997 until May 31, 2007, death or emigration, whichever came first. Mortality data was obtained from the Swedish Death Register using participants' unique national registration number.

\section{Statistical analyses}

Pearson's chi-squared tests and one-way anova models were used to compare the differences between frequencies and means among different levels of total physical activity, respectively. A Cox proportional hazards regression model with age as the underlying time variable, was fitted to estimate hazard ratios (HRs) with $95 \%$ confidence intervals (CIs) of all-cause mortality at different levels of total physical activity, BMI, WHR, waist circumference and their combinations, as compared with the reference category, normal weight with high physical activity. Ties were handled using the Breslow 
method. The 'proportional hazards assumption' in the Cox regression model was assessed by using the scaled Schoenfeld residuals, based on the martingale and deviance residuals. We first studied the graphical plots and then carried out formal statistical tests of their independence over time.

Men and women were analyzed separately. The effect of physical activity, BMI, waist hip ratio, and waist circumference was studied using two sets of Cox models: adjusted only by age at enrollment, and adjusted by age at enrollment plus potential confounders. For men we included cigarette smoking, alcohol drinking, use of vitamin and mineral supplements, and level of education. For women, we also added use of contraceptive pills and hormone replacement therapy. Waist circumference was in an additional analysis adjusted for BMI. Linear trends of HRs were tested by using the median value of each category as a single ordinal variable in the Cox regression model. Interactions between total physical activity and BMI, WHR or waist circumference were assessed by including the cross-product interaction term with the main effect terms in the Cox regression model.

In addition, to better study the functional form of the association of total physical activity, BMI, WHR, and waist circumference with death, a flexible regression model was considered, based on restricted cubic splines, with 4 knots, corresponding to the $5^{\text {th }}, 25^{\text {th }}$, $75^{\text {th }}$, and $95^{\text {th }}$ percentiles of the variables.

Statistical significance of interaction was tested using the likelihood ratio test by comparing nested models with and without such term. We also used a graphical technique 
recently proposed. It is called subpopulation treatment-effect pattern plot (STEPP) [43]. Using this technique, we produced a nonparametric estimate of the physical activity effect, simplified to a binary variable (low/high) within strata defined by BMI, WHR and waist circumference groups. This method is useful for identifying interactions between an exposure binary variable and a continuous covariate of interest. Having several subpopulations, with overlapping tails, the overall effect for the entire sample is visible in the middle part of the plot. With increasing distance from the center, subjects with high values of the covariate are removed from the left and subjects with low values of the covariate are removed from the right.

In order to avoid the influence of a potential bias due to early mortality in individuals with low physical activity and low BMI caused by potential sub-clinical illness, the analyses were repeated after excluding the first two years of follow-up, current/previous smokers and subjects who had lost weight and become underweight (BMI $<18.5 \mathrm{~kg} / \mathrm{m}^{2}$ ) between the age of 20 years and age at baseline.

The proportion of missing BMI, WHR and waist circumference values was 4.8, 26.8 and $26 \%$ respectively. For the physical activity score, $1.25 \%$ of the participants did not respond on any of the specific levels of activities. The percentage of missing values for the other variables that were used in the multivariate models was relatively low, always lower than $5 \%$.

All statistical analyses were performed with STATA version 11.0 (Stata Corporation, College Station, TX, USA). All reported probabilities ( $p$-values) were two-sided and less 
than 0.05 was considered statistically significant.

\section{Results}

According to Statistics Sweden, the initial cohort members (before exclusions), were less educated; $38.9 \%$ had only compulsory schooling, compared to $22.2 \%$ in the general Swedish population in 1997 . They were also less likely to be smokers, $9.4 \%$ compared to $19.2 \%$ of Swedes aged 16-84 at that time. These proportions slightly decreased once selection criteria were applied. Baseline characteristics of subjects (divided into three different total physical activity levels) are shown in Table 1. In general, sedentary men were more likely to be smokers. Both men and women with a high level of physical activity were significantly younger and less educated. The prevalence of alcohol drinking was significantly lower in physically inactive women, but there were no significant differences in alcohol intake across different physical activity levels in men. Table 1 here.

During 9.7 years of follow-up, there were 1943 deaths, $4.8 \%$ of the total sample (1121 males and 822 females). The mortality rates and HRs of all-cause death for total physical activity are illustrated in Table 2. Compared with a low level of physical activity, multivariate-adjusted HRs associated with medium and high physical activity levels were 0.76 (95\% CI: 0.68-0.94) and 0.75 (95\% CI: 0.63-0.90) in men. This pattern was not seen in women. Table 2 here.

Compared with normal weight, multivariate-adjusted HRs associated with overweight and obesity were 1.12 (95\% CI: 0.97-1.30), and 1.62 (95\% CI: 1.21-2.17) in men, and 1.02 (95\% CI: 0.85-1.22) and 1.35 (95\% CI: 1.02-1.78) in women, respectively (Table 3). 
Table 3 here.

WHR was not significantly associated with all-cause mortality risk, but tended to increase the risk in both men and women (Table 4). From the smoothed plot it is apparent that the effect levels off for high values of WHR in both sexes (Figure 1). Hip circumference was not associated with all-cause mortality risk either (data not shown). Compared with a healthy waist circumference, multivariate-adjusted HRs associated with central obesity were 1.30 in men, and 1.35 in women, respectively. The $p$ value for linear trend was statistically significant in both genders (Table 5), but as seen from the graph (Figure 1) careful interpretation must be paid in this case. Furthermore, when adjusting the effect of waist circumference for BMI, the multivariate-adjusted HRs decreased to 1.10, 95\% CI: 0.85-1.42 among men and 1.26, 95\% CI: 0.96-1.65 among women. Given these confidence intervals, the change was not substantial. Table 4, 5 and figure 1 here.

The statistical analysis of the combined effect of physical inactivity and anthropometric measures on all cause-mortality risk did not reveal a consistent pattern of interaction between the factors being investigated. The joint effects, based on the underlying categorical variables (BMI, WHR and waist circumference) are shown in Figure 2. Figure 2 here.

The negative combined effect of inactivity and rising waist circumference in women was captured by a hazard ratio increasing from 1.59 (95\% CI: 1.09-2.34) to 1.71 (95\% CI: 1.16-2.51) and 1.97 (95\% CI: 1.35-2.89) compared to women with low waist circumference and high physical activity $(p$ for interaction $<0.05)$. A less clear effect $(p$ 
for interaction $=0.13)$ was seen for men, with a mortality hazard ratio of $1.68(95 \% \mathrm{CI}$ : 1.25-2.27) when comparing inactive men with high waist circumference to physically active men with low waist circumference. There were no significant interactions between physical inactivity and BMI ( $p=0.25$ in men and 0.36 in women), or physical inactivity and WHR ( $p=0.33$ in men and 0.79 in women). But in the absence of interaction the two risk factors are additive; comparing men with a normal BMI and high total physical activity, to sedentary men with a BMI over 30, the latter group had a multivariate-adjusted HR of 1.80 (95\% CI: 1.19-2.74).

In Figure 3 we show the results obtained by fitting the STEPP to our data once we stratified by gender. Independently of strictly statistical significance for the interaction, the plots suggest that the protective effect of high physical activity is somewhat weaker for lean subjects. Figure 3 here.

The analyses were repeatedly performed after excluding the person-years and deaths occurring during the first 2 years of follow-up, previous and current smokers, and individuals who lost significant weight (as defined earlier) before enrolling in the present cohort study. None of the aforementioned relation patterns were appreciably altered among women, however, the multivariate-adjusted HR increased among obese men with a $\mathrm{BMI} \geq 30$ to 2.59 (95\% CI: $1.73-3.87$ ) or a waist circumference $\geq 102 \mathrm{~cm} 1.54$ (95\% CI: $1.16-2.05)$.

The moderate proportion of missing values for BMI, and the higher proportion of missing values for the waist circumference and WHR were not associated with our main 
confounders. As a consequence, statistical inference barely changed when imputation methods were applied (results not shown). The assessment of proportional hazard in Cox regression was fulfilled in all fitted models.

\section{Discussion}

In our study, obese men with a low level of total physical activity had an 80 percent increased all-cause mortality risk compared with normal weight men with high level of total physical activity. Women with a high waist circumference and a low level of total physical activity had an almost doubled all-cause mortality risk compared with women who had a low waist circumference and high level of total physical activity.

Several prospective studies have evaluated the joint effects of physical activity and obesity with total mortality. In a cohort of middle-aged and elderly men, physically active obese and overweight men had a $60 \%$ higher death rate from all causes than lean active men. Furthermore, the high level of physical activity did not compensate the excess mortality associated with obesity or overweight [44]. The Lipid Research Clinics Study assessed the effects of fitness and fatness on longevity [45]. Although there were no significant interactions on all-cause mortality between fitness and fatness in either men or women, there was an increased multivariate-adjusted mortality risk both in men and women who were categorized as fit-fat, unfit-unfat, and unfit-fat compared with those categorized as fit-unfat. In our study, we did not assess fitness, although physical activity is one of the primary determinants of fitness. Even moderate levels of physical activity can improve cardiorespiratory fitness to a level associated with substantial health benefits [46]. 
BMI, WHR and waist circumference are all measures of adiposity and are positively associated with total mortality [1], but such associations may be sex, and/or age dependent. The Buffalo Health Study demonstrated that there was an increased risk of death associated with increased BMI in men, but not in women [47]. The Malmö Diet and Cancer Study reported a significant multivariate-adjusted dose-response relationship between WHR (independent of overall body fat) and all-cause mortality in women, but not in men [48]. Recently the European Prospective Investigation into Cancer and Nutrition (EPIC) found the highest relative risk of death among the participants in the lowest third of BMI and the highest quintile of waist circumference or WHR, independent of gender [23]. Bender et al. showed that mortality associated with obesity decreased with age in both sexes [49], and Gulsvik et al. found that a low BMI was an independent risk factor of mortality in elderly in a large population sample followed for 42 years [50]. Another prospective study of mortality showed that BMI had U-shaped and negative linear functions in younger and older women, respectively, but WHR had positive linear trends both in younger and older women [51]. Recently, a Danish study of anthropometric measures found that hip circumference was positively associated with venous thromboembolism in women [52]. We could not see an association between hip circumference and mortality in our study.

However, we found an age and multivariate adjusted dose-response risk of total mortality with increasing BMI and waist circumference, which was significant in both men and women. No clear pattern was seen for WHR, for either gender - but WHR may be more difficult to interpret since it could reflect an effect of larger waist as well as a smaller hip 
circumference [21], while waist circumference alone is more strongly correlated with visceral adiposity [53].

Some prospective studies $[4-10,54]$ and a meta-analysis [1] have suggested a J- or U-shaped relationship between BMI and total mortality. A review of guidelines for a healthy weight by Willett et al. [19] suggests that reverse causation and confounding factors (particularly smoking) could distort this relationship. As such, in our analyses, we excluded subjects with cardiovascular diseases (ICD10 codes: I00-I99) and any types of cancer at baseline and carried out multivariate adjustment for potential confounders, including smoking status. The sensitivity analyses excluding death occurring during the first 2 years of follow-up, previous and current smokers and subjects who had lost significant weight since the age of 20 , did not alter the association, but rather enhanced them among men.

Our study has several strengths. First, this was a prospective homogeneous populationbased study comprising a large number of both men and women. Second, the period of follow-up was sufficiently long, almost 10 years, during which mortality were ascertained without losses to follow-up. Third, we use a validated instrument designed to capture the whole spectrum of habitual physical activity frequently missed in other studies using more simplified methods of inquiry.

Several potential limitations of our study warrant further consideration. All data were obtained by self-report at baseline, which might result in distorted inter-relationships between physical activity, BMI, WHR, waist circumference and total mortality, because 
obese people commonly overestimate their physical activity [15] and underestimate self-measured WHR [55]. Overestimation of height and underestimation of weight might also result in misclassification of BMI, although such errors tend to be small $[56,57]$. Nevertheless, self-measured and self-reported weight, waist and hip circumference have been found to be reasonably valid. Rimm at al. [58] conducted a validation study where 123 men (aged 40-75 years) and 140 women (aged 41-65 years) were asked to self-report weight, waist and hip circumference in a questionnaire. When comparing this to standardized measurements the crude Pearson correlation coefficients were between 0.69-0.97 for men and 0.7-0.97 for women.

The proportion of missing BMI values was rather low, and men and women had the same propensity in reporting their BMI. The distribution of BMI was virtually identical among those who did and did not report waist circumference and waist hip ratio. However, women were more often able to report their waist circumference and waist hip ratio. It has previously been shown that women are more willing to respond to questionnaires overall [59-61], and this might also apply to response pattern of individual questions.

The lack of follow-up of anthropometric measures is further a limitation of this study. Body fat distribution may have changed during the follow-up, but this is usually a slow process. A longitudinal study showed that the variation of body weight and adipose tissue distribution was surprisingly stable throughout a similar time span as our study [62]. There is a chance that changes in physical activity over time could influence our results. Other unmeasured confounders might also bias the observed associations between total physical activity, BMI, WHR, waist circumference and total mortality. 
We conclude that both physical inactivity and adiposity increase total mortality risk independently. Although there are no significant interactions between physical inactivity and anthropometric measures, the additive effect of being both obese and physically inactive increase mortality risk further.

\section{Acknowledgements}

This work was supported by the companies ICA AB and Ericsson. We would like to thank Statistics Sweden for scanning the questionnaires. We also would like to express sincere gratitude to the Swedish Cancer Society and volunteers who worked with the National March. 


\section{References}

1. Katzmarzyk PT, Janssen I, Ardern CI. Physical inactivity, excess adiposity and premature mortality. Obes Rev 2003; 4: 257-290.

2. Obesity: preventing and managing the global epidemic. Report of a WHO consultation. World Health Organ Tech Rep Ser 2000; 894: i-xii, 1-253.

3. Brundtland GH. From the World Health Organization. Reducing risks to health, promoting healthy life. Jama 2002; 288: 1974.

4. Calle EE, Thun MJ, Petrelli JM, Rodriguez C, Heath CW, Jr. Body-mass index and mortality in a prospective cohort of U.S. adults. N Engl J Med 1999; 341: 1097-1105.

5. Yuan JM, Ross RK, Gao YT, Yu MC. Body weight and mortality: a prospective evaluation in a cohort of middle-aged men in Shanghai, China. Int J Epidemiol 1998; 27: 824-832.

6. Durazo-Arvizu RA, McGee DL, Cooper RS, Liao Y, Luke A. Mortality and optimal body mass index in a sample of the US population. Am J Epidemiol 1998; 147: 739-749. 7. Adams KF, Schatzkin A, Harris TB, Kipnis V, Mouw T, Ballard-Barbash R, Hollenbeck A, Leitzmann MF. Overweight, obesity, and mortality in a large prospective cohort of persons 50 to 71 years old. N Engl J Med 2006; 355: 763-778.

8. Corrada MM, Kawas CH, Mozaffar F, Paganini-Hill A. Association of body mass index and weight change with all-cause mortality in the elderly. Am J Epidemiol 2006; 163: 938-949.

9. Gu D, He J, Duan X, Reynolds K, Wu X, Chen J, Huang G, Chen CS, Whelton PK. Body weight and mortality among men and women in China. Jama 2006; 295: 776-783. 10. Jee SH, Sull JW, Park J, Lee SY, Ohrr H, Guallar E, Samet JM. Body-mass index and mortality in Korean men and women. N Engl J Med 2006; 355: 779-787. 
11. Neovius M, Sundstrom J, Rasmussen F. Combined effects of overweight and smoking in late adolescence on subsequent mortality: nationwide cohort study. Bmj 2009; 338: b496.

12. Whitlock G, Lewington S, Sherliker P, Clarke R, Emberson J, Halsey J, Qizilbash N, Collins R, Peto R. Body-mass index and cause-specific mortality in 900000 adults: collaborative analyses of 57 prospective studies. Lancet 2009; 373: 1083-1096.

13. Stevens J, Cai J, Pamuk ER, Williamson DF, Thun MJ, Wood JL. The effect of age on the association between body-mass index and mortality. N Engl J Med 1998; 338: 1-7. 14. Ajani UA, Lotufo PA, Gaziano JM, Lee IM, Spelsberg A, Buring JE, Willett WC, Manson JE. Body mass index and mortality among US male physicians. Ann Epidemiol 2004; 14: 731-739.

15. Hu FB, Willett WC, Li T, Stampfer MJ, Colditz GA, Manson JE. Adiposity as compared with physical activity in predicting mortality among women. N Engl J Med 2004; 351: 2694-2703.

16. Freedman DM, Ron E, Ballard-Barbash R, Doody MM, Linet MS. Body mass index and all-cause mortality in a nationwide US cohort. Int J Obes (Lond) 2006; 30: 822-829. 17. Diehr P, Bild DE, Harris TB, Duxbury A, Siscovick D, Rossi M. Body mass index and mortality in nonsmoking older adults: the Cardiovascular Health Study. Am J Public Health 1998; 88: 623-629.

18. Haapanen-Niemi N, Miilunpalo S, Pasanen M, Vuori I, Oja P, Malmberg J. Body mass index, physical inactivity and low level of physical fitness as determinants of all-cause and cardiovascular disease mortality--16 y follow-up of middle-aged and elderly men and women. Int J Obes Relat Metab Disord 2000; 24: 1465-1474. 19. Willett WC, Dietz WH, Colditz GA. Guidelines for healthy weight. N Engl J Med 
1999; 341: 427-434.

20. Davey Smith G, Sterne JA, Fraser A, Tynelius P, Lawlor DA, Rasmussen F. The association between BMI and mortality using offspring BMI as an indicator of own BMI: large intergenerational mortality study. Bmj 2009; 339: b5043.

21. Snijder MB, van Dam RM, Visser M, Seidell JC. What aspects of body fat are particularly hazardous and how do we measure them? Int J Epidemiol 2006; 35: 83-92.

22. Chakraborty BM, Chakraborty R. Sensitivity and specificity of body mass index as a definition of the obesity component of metabolic syndrome. Coll Antropol 2007; 31: 943-947.

23. Pischon T, Boeing H, Hoffmann K, Bergmann M, Schulze MB, Overvad K, van der Schouw YT, Spencer E, Moons KG, Tjonneland A, Halkjaer J, Jensen MK, Stegger J, Clavel-Chapelon F, Boutron-Ruault MC, Chajes V, Linseisen J, Kaaks R, Trichopoulou A, Trichopoulos D, Bamia C, Sieri S, Palli D, Tumino R, Vineis P, Panico S, Peeters PH, May AM, Bueno-de-Mesquita HB, van Duijnhoven FJ, Hallmans G, Weinehall L, Manjer J, Hedblad B, Lund E, Agudo A, Arriola L, Barricarte A, Navarro C, Martinez C, Quiros JR, Key T, Bingham S, Khaw KT, Boffetta P, Jenab M, Ferrari P, Riboli E. General and abdominal adiposity and risk of death in Europe. N Engl J Med 2008; 359: 2105-2120. 24. Yusuf S, Hawken S, Ounpuu S, Bautista L, Franzosi MG, Commerford P, Lang CC, Rumboldt Z, Onen CL, Lisheng L, Tanomsup S, Wangai P, Jr., Razak F, Sharma AM, Anand SS. Obesity and the risk of myocardial infarction in 27,000 participants from 52 countries: a case-control study. Lancet 2005; 366: 1640-1649.

25. Wang Y, Rimm EB, Stampfer MJ, Willett WC, Hu FB. Comparison of abdominal adiposity and overall obesity in predicting risk of type 2 diabetes among men. Am J Clin Nutr 2005; 81: 555-563. 
26. Andersen LB, Schnohr P, Schroll M, Hein HO. All-cause mortality associated with physical activity during leisure time, work, sports, and cycling to work. Arch Intern Med 2000; 160: 1621-1628.

27. Gregg EW, Cauley JA, Stone K, Thompson TJ, Bauer DC, Cummings SR, Ensrud KE. Relationship of changes in physical activity and mortality among older women. Jama 2003; 289: 2379-2386.

28. Myers J, Kaykha A, George S, Abella J, Zaheer N, Lear S, Yamazaki T, Froelicher V. Fitness versus physical activity patterns in predicting mortality in men. Am J Med 2004; 117: 912-918.

29. Trolle-Lagerros Y, Mucci LA, Kumle M, Braaten T, Weiderpass E, Hsieh CC, Sandin S, Lagiou P, Trichopoulos D, Lund E, Adami HO. Physical activity as a determinant of mortality in women. Epidemiology 2005; 16: 780-785.

30. Khaw KT, Jakes R, Bingham S, Welch A, Luben R, Day N, Wareham N. Work and leisure time physical activity assessed using a simple, pragmatic, validated questionnaire and incident cardiovascular disease and all-cause mortality in men and women: The European Prospective Investigation into Cancer in Norfolk prospective population study. Int J Epidemiol 2006; 35: 1034-1043.

31. Chakravarty EF, Hubert HB, Lingala VB, Fries JF. Reduced disability and mortality among aging runners: a 21-year longitudinal study. Arch Intern Med 2008; 168: $1638-1646$.

32. Nocon M, Hiemann T, Muller-Riemenschneider F, Thalau F, Roll S, Willich SN. Association of physical activity with all-cause and cardiovascular mortality: a systematic review and meta-analysis. Eur J Cardiovasc Prev Rehabil 2008; 15: 239-246.

33. Oguma Y, Sesso HD, Paffenbarger RS, Jr., Lee IM. Physical activity and all cause 
mortality in women: a review of the evidence. Br J Sports Med 2002; 36: 162-172.

34. Koster A, Harris TB, Moore SC, Schatzkin A, Hollenbeck AR, van Eijk JT, Leitzmann MF. Joint associations of adiposity and physical activity with mortality: the National Institutes of Health-AARP Diet and Health Study. Am J Epidemiol 2009; 169: $1344-1351$.

35. Hu G, Tuomilehto J, Silventoinen K, Barengo NC, Peltonen M, Jousilahti P. The effects of physical activity and body mass index on cardiovascular, cancer and all-cause mortality among 47212 middle-aged Finnish men and women. Int J Obes (Lond) 2005; 29: 894-902.

36. Lagerros YT, Mucci LA, Bellocco R, Nyren O, Balter O, Balter KA. Validity and reliability of self-reported total energy expenditure using a novel instrument. Eur J Epidemiol 2006; 21: 227-236.

37. Lagerros YT, Bellocco R, Adami HO, Nyren O. Measures of physical activity and their correlates: the Swedish National March Cohort. Eur J Epidemiol 2009; 24: 161-169. 38. Ainsworth BE, Haskell WL, Leon AS, Jacobs DR, Jr., Montoye HJ, Sallis JF, Paffenbarger RS, Jr. Compendium of physical activities: classification of energy costs of human physical activities [see comments]. Med Sci Sports Exerc 1993; 25: 71-80.

39. Ainsworth BE, Haskell WL, Whitt MC, Irwin ML, Swartz AM, Strath SJ, O'Brien WL, Bassett DR, Jr., Schmitz KH, Emplaincourt PO, Jacobs DR, Jr., Leon AS.

Compendium of physical activities: an update of activity codes and MET intensities. Med Sci Sports Exerc 2000; 32: S498-504.

40. Bexelius C, Lof M, Sandin S, Trolle Lagerros Y, Forsum E, Litton JE. Measures of physical activity using cell phones: validation using criterion methods. J Med Internet Res; 12: e2. 
41. Egger GJ, Binns AF, Rossner SR. The emergence of "lifestyle medicine" as a structured approach for management of chronic disease. Med J Aust 2009; 190: 143-145. 42. Alberti KG, Zimmet P, Shaw J. The metabolic syndrome--a new worldwide definition. Lancet 2005; 366: 1059-1062.

43. Bonetti M, Gelber RD. A graphical method to assess treatment-covariate interactions using the Cox model on subsets of the data. Statistics in medicine 2000; 19: 2596-2609. 44. Orsini N, Bellocco R, Bottai M, Pagano M, Michaelsson K, Wolk A. Combined effects of obesity and physical activity in predicting mortality among men. J Intern Med 2008; 264: 442-451.

45. Stevens J, Cai J, Evenson KR, Thomas R. Fitness and fatness as predictors of mortality from all causes and from cardiovascular disease in men and women in the lipid research clinics study. Am J Epidemiol 2002; 156: 832-841.

46. Stofan JR, DiPietro L, Davis D, Kohl HW, 3rd, Blair SN. Physical activity patterns associated with cardiorespiratory fitness and reduced mortality: the Aerobics Center Longitudinal Study. Am J Public Health 1998; 88: 1807-1813.

47. Dorn JM, Schisterman EF, Winkelstein W, Jr., Trevisan M. Body mass index and mortality in a general population sample of men and women. The Buffalo Health Study. Am J Epidemiol 1997; 146: 919-931.

48. Lahmann PH, Lissner L, Gullberg B, Berglund G. A prospective study of adiposity and all-cause mortality: the Malmo Diet and Cancer Study. Obes Res 2002; 10: 361-369. 49. Bender R, Jockel KH, Trautner C, Spraul M, Berger M. Effect of age on excess mortality in obesity. JAMA 1999; 281: 1498-1504.

50. Gulsvik AK, Thelle DS, Mowe M, Wyller TB. Increased mortality in the slim elderly: a 42 years follow-up study in a general population. Eur J Epidemiol 2009; 24: 683-690. 
51. Lindqvist P, Andersson K, Sundh V, Lissner L, Bjorkelund C, Bengtsson C.

Concurrent and separate effects of body mass index and waist-to-hip ratio on 24-year mortality in the Population Study of Women in Gothenburg: evidence of age-dependency. Eur J Epidemiol 2006; 21: 789-794.

52. Severinsen MT, Kristensen SR, Johnsen SP, Dethlefsen C, Tjonneland A, Overvad K. Anthropometry, body fat, and venous thromboembolism: a Danish follow-up study.

Circulation 2009; 120: 1850-1857.

53. Onat A, Avci GS, Barlan MM, Uyarel H, Uzunlar B, Sansoy V. Measures of abdominal obesity assessed for visceral adiposity and relation to coronary risk. Int J Obes Relat Metab Disord 2004; 28: 1018-1025.

54. Meyer HE, Sogaard AJ, Tverdal A, Selmer RM. Body mass index and mortality: the influence of physical activity and smoking. Med Sci Sports Exerc 2002; 34: 1065-1070. 55. Roberts CA, Wilder LB, Jackson RT, Moy TF, Becker DM. Accuracy of self-measurement of waist and hip circumference in men and women. J Am Diet Assoc 1997; 97: 534-536.

56. Palta M, Prineas RJ, Berman R, Hannan P. Comparison of self-reported and measured height and weight. Am J Epidemiol 1982; 115: 223-230.

57. Stewart AW, Jackson RT, Ford MA, Beaglehole R. Underestimation of relative weight by use of self-reported height and weight. Am J Epidemiol 1987; 125: 122-126. 58. Rimm EB, Stampfer MJ, Colditz GA, Chute CG, Litin LB, Willett WC. Validity of self-reported waist and hip circumferences in men and women. Epidemiology 1990; 1: 466-473.

59. Hazell ML, Morris JA, Linehan MF, Frank PI, Frank TL. Factors influencing the response to postal questionnaire surveys about respiratory symptoms. Prim Care Respir J 
2008.

60. Feveile H, Olsen O, Hogh A. A randomized trial of mailed questionnaires versus telephone interviews: response patterns in a survey. BMC Med Res Methodol 2007; 7: 27.

61. Eaker S, Bergstrom R, Bergstrom A, Adami HO, Nyren O. Response rate to mailed epidemiologic questionnaires: a population-based randomized trial of variations in design and mailing routines. Am J Epidemiol 1998; 147: 74-82.

62. Katzmarzyk PT, Perusse L, Malina RM, Bouchard C. Seven-year stability of indicators of obesity and adipose tissue distribution in the Canadian population. Am $\mathrm{J}$ Clin Nutr 1999; 69: 1123-1129. 
Figure 1. Adjusted Hazard Ratios (HR) to study the association between overall mortality and physical activity (MET*h/day), body-mass index (BMI), waist-to-hip ratio (WHR), and waist circumference. Solid lines are the HRs and dashed lines are 95\% confidence intervals derived from restricted cubic spline regression, with knots at the $5^{\text {th }}$, $25^{\text {th }}, 75^{\text {th }}$, and $95^{\text {th }}$ percentiles of the sex-specific distribution of each anthropometric variable. Reference values are the median of the corresponding reference class. Plots, on logarithmic scale, range around $99 \%$ of the distribution.

Figure 2. Adjusted Hazard Ratios and 95\% confidence intervals for sex specific overall mortality, as a function of tertiles of physical activity (PA) and body mass index (BMI), waist-to-hip ratio (WHR), and waist circumference estimated by Cox proportional hazard regression. The reference group is the category associated with high physical activity and normal body mass index, low waist hip ratio and low waist circumference.

Figure 3. Hazard Ratios and 95\% confidence intervals to study the effect of physical activity (high/low) as a continuous function of body mass index (BMI), waist-to-hip ratio (WHR), and waist circumference, on total mortality, using STEPPS (subpopulation treatment-effect pattern plot, the tail oriented variant), adjusting for age at enrollment, cigarette smoking status, alcohol drinking, vitamins and mineral use, and educational level in men, and for women additionally adjusted for contraceptive pill use and hormone therapy replacement. 
Table 1. Selected baseline characteristics of participants, categorized by total physical activity levels. The Swedish National March Cohort.

\begin{tabular}{|c|c|c|c|c|}
\hline \multirow{2}{*}{ Variables } & \multicolumn{3}{|c|}{ Total physical activity } & \multirow{2}{*}{$p$-value } \\
\hline & Low & Medium & High & \\
\hline \multicolumn{5}{|l|}{ Male } \\
\hline Number of participants & 4862 & 4862 & 4861 & \\
\hline Age, years (median, IQR) & $54.8,26.4$ & $54.2,25.3$ & $53.3,32.1$ & $<0.001$ \\
\hline Height, meters (median, IQR) & $1.78,0.9$ & $1.78,0.9$ & $1.78,0.9$ & 0.057 \\
\hline Weight, kg (median, IQR) & $79.0,15.0$ & $78.0,13.0$ & $78.0,13.0$ & $<0.001$ \\
\hline BMI, kg/m² (median, IQR) & $28.8,4.0$ & $24.7,3.7$ & $24.5,3.7$ & $<0.001$ \\
\hline $\begin{array}{l}\text { Waist circumference, } \mathrm{cm} \text { (median, } \\
\text { IQR) }\end{array}$ & $94.0,12.0$ & $92.0,11.0$ & $92.0,13.0$ & $<0.001$ \\
\hline $\begin{array}{l}\text { Hip circumference, } \mathrm{cm} \text { (median, } \\
\text { IQR) }\end{array}$ & $100.3 \pm 9.4$ & $99.2 \pm 9.0$ & $98.7 \pm 9.5$ & $<0.001$ \\
\hline WHR (median, IQR) & $0.94 \pm 0.09$ & $0.93 \pm 0.09$ & $0.93 \pm 0.09$ & $<0.001$ \\
\hline Education $(>12$ years, \%) & 29.4 & 26.8 & 13.9 & $<0.001$ \\
\hline Current smoking (\%) & 8.3 & 7.0 & 8.0 & $<0.001$ \\
\hline Alcohol drinking $(\%)$ & 89.1 & 89.7 & 89.0 & 0.513 \\
\hline $\begin{array}{l}\text { Use of vitamin and mineral } \\
\text { supplements }(\%)\end{array}$ & 37.8 & 39.5 & 37.7 & 0.120 \\
\hline \multicolumn{5}{|l|}{ Female } \\
\hline Number of participants & 8716 & 8717 & 8711 & \\
\hline Age, years (median, IQR) & $51.0 \pm 16.6$ & $47.7 \pm 15.3$ & $46.9 \pm 15.8$ & $<0.001$ \\
\hline Height, meters (median, IQR) & $1.65 \pm 0.06$ & $1.66 \pm 0.06$ & $1.66 \pm 0.06$ & 0.001 \\
\hline Weight, kg (median, IQR) & $67.4 \pm 11.2$ & $66.2 \pm 10.6$ & $65.5 \pm 10.4$ & $<0.001$ \\
\hline BMI, $\mathrm{kg} / \mathrm{m}^{2}$ (median, IQR) & $24.6 \pm 3.9$ & $24.1 \pm 3.7$ & $23.9 \pm 3.6$ & $<0.001$ \\
\hline $\begin{array}{l}\text { Waist circumference, } \mathrm{cm} \text { (median, } \\
\mathrm{IQR} \text { ) }\end{array}$ & $82.0 \pm 10.8$ & $80.2 \pm 10.2$ & $79.2 \pm 9.8$ & $<0.001$ \\
\hline $\begin{array}{l}\text { Hip circumference, } \mathrm{cm} \text { (median, } \\
\text { IQR) }\end{array}$ & $101.0 \pm 10.3$ & $99.6 \pm 12.1$ & $98.5 \pm 12.8$ & $<0.001$ \\
\hline WHR (median, IQR) & $0.81 \pm 0.09$ & $0.81 \pm 0.10$ & $0.81 \pm 0.10$ & 0.002 \\
\hline Education $(>12$ years, \%) & 28.0 & 34.0 & 27.8 & $<0.001$ \\
\hline Current smoking $(\%)$ & 8.70 & 8.13 & 9.09 & 0.020 \\
\hline Alcohol drinking $(\%)$ & 84.7 & 88.0 & 86.7 & $<0.001$ \\
\hline $\begin{array}{l}\text { Use of vitamin and mineral } \\
\text { supplements }(\%)\end{array}$ & 52.4 & 53.4 & 54.0 & 0.114 \\
\hline Use of contraceptive pill (\%) & 61.1 & 67.5 & 65.5 & $<0.001$ \\
\hline Hormone replacement therapy (\%) & 29.4 & 25.5 & 23.9 & $<0.001$ \\
\hline
\end{tabular}

BMI = Body Mass Index

WHR = Waist-to-Hip Ratio

$\mathrm{IQR}=$ Interquartile range 
Table 2. Mortality rates and hazard ratios of all-cause death for total physical activity. The Swedish National March Cohort.

\begin{tabular}{|c|c|c|c|c|}
\hline & \multicolumn{3}{|c|}{ Total physical activity } & \multirow{2}{*}{$\begin{array}{l}p \text { for } \\
\text { trend }\end{array}$} \\
\hline & Low & Medium & High & \\
\hline \multicolumn{5}{|l|}{ Male } \\
\hline Number of deaths & 470 & 333 & 318 & \\
\hline Person-years & 44652 & 45541 & 45380 & \\
\hline${ }^{\mathrm{a}}$ Mortality rate & 1001.39 & 773.18 & 762.28 & \\
\hline b $\mathrm{HR}(95 \% \mathrm{CI})$ & 1.00 (reference) & $0.82(0.71-0.94)$ & $0.82(0.71-0.95)$ & 0.016 \\
\hline c $\mathrm{HR}(95 \% \mathrm{CI})$ & 1.00 (reference) & $0.76(0.68-0.94)$ & $0.75(0.63-0.90)$ & 0.003 \\
\hline \multicolumn{5}{|l|}{ Female } \\
\hline Number of deaths & 384 & 217 & 221 & \\
\hline Person-years & 82731 & 83294 & 82832 & \\
\hline${ }^{\mathrm{a}}$ Mortality rate & 375.80 & 290.9 & 309.31 & \\
\hline b $\mathrm{HR}(95 \% \mathrm{CI})$ & 1.00 (reference) & $0.85(0.72-1.00)$ & $0.91(0.77-1.08)$ & 0.366 \\
\hline c $\mathrm{HR}(95 \% \mathrm{CI})$ & 1.00 (reference) & $0.91(0.74-1.11)$ & $0.94(0.77-1.15)$ & 0.595 \\
\hline
\end{tabular}

\footnotetext{
${ }^{a}$ Mortality rates were presented as per 100,000 person-years, standardized to the age distribution of person-years experienced by all study participants using 5-year age categories.

${ }^{\mathrm{b}}$ Adjusted for age at enrollment.

${ }^{c}$ Adjusted for age at enrollment, body mass index, cigarette smoking status, alcohol drinking, use of vitamins and minerals, and educational level in men; further adjusted for contraceptive pill use and hormone therapy replacement in women.

HR = Hazard Ratio

$\mathrm{CI}=$ Confidence Interval
} 
Table 3. Mortality rates and hazard ratios of all-cause death for body mass index. The Swedish National March Cohort.

\begin{tabular}{|c|c|c|c|c|}
\hline & \multicolumn{3}{|c|}{ BMI } & \multirow{2}{*}{$\begin{array}{l}p \text { for } \\
\text { trend }\end{array}$} \\
\hline & $\mathrm{BMI}<25$ & BMI 25-29.9 & $\mathrm{BMI} \geq 30$ & \\
\hline \multicolumn{5}{|l|}{ Male } \\
\hline $\begin{array}{l}\text { Number of } \\
\text { deaths }\end{array}$ & 546 & 441 & 67 & \\
\hline Person-years & 71179 & 51112 & 7386 & \\
\hline${ }^{\mathrm{a}}$ Mortality rate & 817.42 & 830.77 & 1083.57 & \\
\hline${ }^{\mathrm{b}} \mathrm{HR}(95 \% \mathrm{CI})$ & 1.00 (reference) & $1.09(0.96-1.24)$ & $1.65(1.28-2.14)$ & 0.006 \\
\hline${ }^{\mathrm{c}} \mathrm{HR}(95 \% \mathrm{CI})$ & 1.00 (reference) & $1.12(0.97-1.30)$ & $1.62(1.21-2.17)$ & 0.023 \\
\hline \multicolumn{5}{|l|}{ Female } \\
\hline $\begin{array}{l}\text { Number of } \\
\text { deaths }\end{array}$ & 447 & 231 & 79 & \\
\hline Person-years & 153270 & 65495 & 18201 & \\
\hline${ }^{\mathrm{a}}$ Mortality rate & 332.09 & 298.95 & 453.74 & \\
\hline${ }^{\mathrm{b}} \mathrm{HR}(95 \% \mathrm{CI})$ & 1.00 (reference) & $0.92(0.78-1.07)$ & $1.34(1.05-1.70)$ & 0.028 \\
\hline${ }^{\mathrm{c}} \mathrm{HR}(95 \% \mathrm{CI})$ & 1.00 (reference) & $1.02(0.85-1.22)$ & $1.35(1.02-1.78)$ & 0.016 \\
\hline
\end{tabular}

${ }^{\mathrm{a}}$ Mortality rates were presented as per 100,000 person-years, standardized to the age distribution of person-years experienced by all study participants using 5-year age categories.

${ }^{\mathrm{b}}$ Adjusted for age at enrollment.

${ }^{c}$ Adjusted for age at enrollment, physical activity, cigarette smoking status, alcohol drinking, use of vitamins and minerals, and educational level in men; further adjusted for contraceptive pill use and hormone therapy replacement in women.

${ }^{\mathrm{d}} p$ for trend was across overweight and obesity compared with normal weight.

HR = Hazard Ratio

$\mathrm{CI}=$ Confidence Interval 
Table 4. Mortality rates and hazard ratios of all-cause death for waist-hip ratio. The Swedish National March Cohort.

\begin{tabular}{|c|c|c|c|}
\hline & \multicolumn{2}{|c|}{ WHR } & \multirow[b]{2}{*}{$p$-value } \\
\hline & $\leq 1$ & $>1$ & \\
\hline \multicolumn{4}{|l|}{ Male } \\
\hline Number of deaths & 741 & 95 & \\
\hline Person-years & 79600 & 10017 & \\
\hline${ }^{\mathrm{a}}$ Mortality rate & 809.58 & 817.94 & \\
\hline b $\mathrm{HR}(95 \% \mathrm{CI})$ & 1.00 (reference) & $1.01(0.82-1.26)$ & 0.893 \\
\hline \multirow[t]{3}{*}{${ }^{\mathrm{c}} \mathrm{HR}(95 \% \mathrm{CI})$} & 1.00 (reference) & $1.18(0.94-1.49)$ & 0.159 \\
\hline & \multicolumn{2}{|c|}{ WHR } & \\
\hline & $\leq 0.8$ & $>0.8$ & $p$-value \\
\hline \multicolumn{4}{|l|}{ Female } \\
\hline Number of deaths & 256 & 404 & \\
\hline Person-years & 93532 & 98557 & \\
\hline${ }^{\mathrm{a}}$ Mortality rate & 289.43 & 340.72 & \\
\hline${ }^{\mathrm{b}} \mathrm{HR}(95 \% \mathrm{CI})$ & 1.00 (reference) & $1.13(0.97-1.33)$ & 0.140 \\
\hline${ }^{\mathrm{c}} \mathrm{HR}(95 \% \mathrm{CI})$ & 1.00 (reference) & $1.18(0.98-1.41)$ & 0.076 \\
\hline
\end{tabular}

${ }^{a}$ Mortality rates were presented as per 100,000 person-years, standardized to the age distribution of person-years experienced by all study participants using 5-year age categories.

${ }^{\mathrm{b}}$ Adjusted for age at enrollment.

${ }^{\mathrm{c}}$ Adjusted for age at enrollment, physical activity, cigarette smoking status, alcohol drinking, use of vitamins and minerals, and educational level in men; further adjusted for contraceptive pill use and hormone therapy replacement in women.

HR = Hazard Ratio

$\mathrm{CI}=$ Confidence Interval 
Table 5. Mortality rates and hazard ratios of all-cause death for waist circumference. The Swedish National March Cohort.

\begin{tabular}{|c|c|c|c|c|}
\hline \multicolumn{5}{|c|}{ WAIST } \\
\hline & $<94 \mathrm{~cm}$ & $\geq 94$ to $102 \mathrm{~cm}$ & $\geq 102 \mathrm{~cm}$ & $\begin{array}{l}p \text {-value } \\
\text { for trend }\end{array}$ \\
\hline \multicolumn{5}{|l|}{ Male } \\
\hline $\begin{array}{l}\text { Number of } \\
\text { deaths }\end{array}$ & 400 & 257 & 199 & \\
\hline Person-years & 48840 & 26448 & 15935 & \\
\hline${ }^{\mathrm{a}}$ Mortality rate & 783.83 & 755.56 & 999.94 & \\
\hline${ }^{\mathrm{b}} \mathrm{HR}(95 \% \mathrm{CI})$ & 1.00 (reference) & $1.00(0.85-1.17)$ & $1.34(1.13-1.59)$ & 0.004 \\
\hline \multirow[t]{3}{*}{${ }^{\mathrm{c}} \mathrm{HR}(95 \% \mathrm{CI})$} & 1.00 (reference) & $0.97(0.80-1.16)$ & $1.30(1.07-1.58)$ & 0.032 \\
\hline & \multicolumn{4}{|c|}{ WAIST } \\
\hline & $<80 \mathrm{~cm}$ & $\geq 80$ to $>88 \mathrm{~cm}$ & $\geq 88 \mathrm{~cm}$ & $\begin{array}{l}p \text {-value } \\
\text { for trend }\end{array}$ \\
\hline
\end{tabular}

\section{Female}

Number of

deaths

Person-years

${ }^{\text {a }}$ Mortality rate

${ }^{\mathrm{b}} \mathrm{HR}(95 \% \mathrm{CI})$

${ }^{\mathrm{a}}$ Mortality rates were presented as per 100,000 person-years, standardized to the age distribution of person-years experienced by all study participants using 5-year age categories.

${ }^{\mathrm{b}}$ Adjusted for age at enrollment.

${ }^{c}$ Adjusted for age at enrollment, physical activity, cigarette smoking status, alcohol drinking, use of vitamins and minerals, and educational level in men; further adjusted for contraceptive pill use and hormone therapy replacement in women.

${ }^{\mathrm{d}} p$ for trend was across overweight and obesity compared with normal weight as measured by waist.

HR = Hazard Ratio

$\mathrm{CI}=$ Confidence Interval

\section{Figure 1}



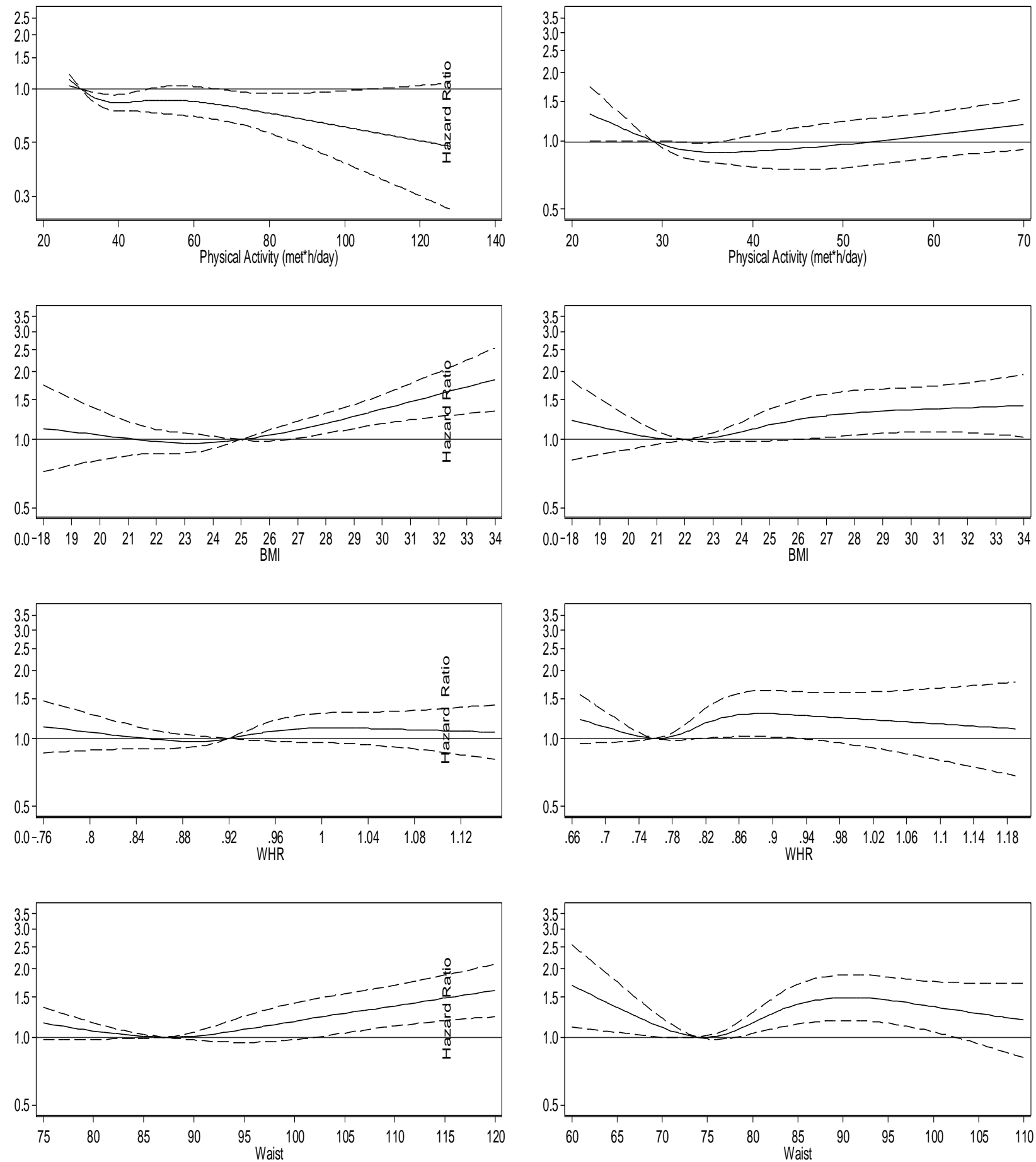


\section{Figure2}
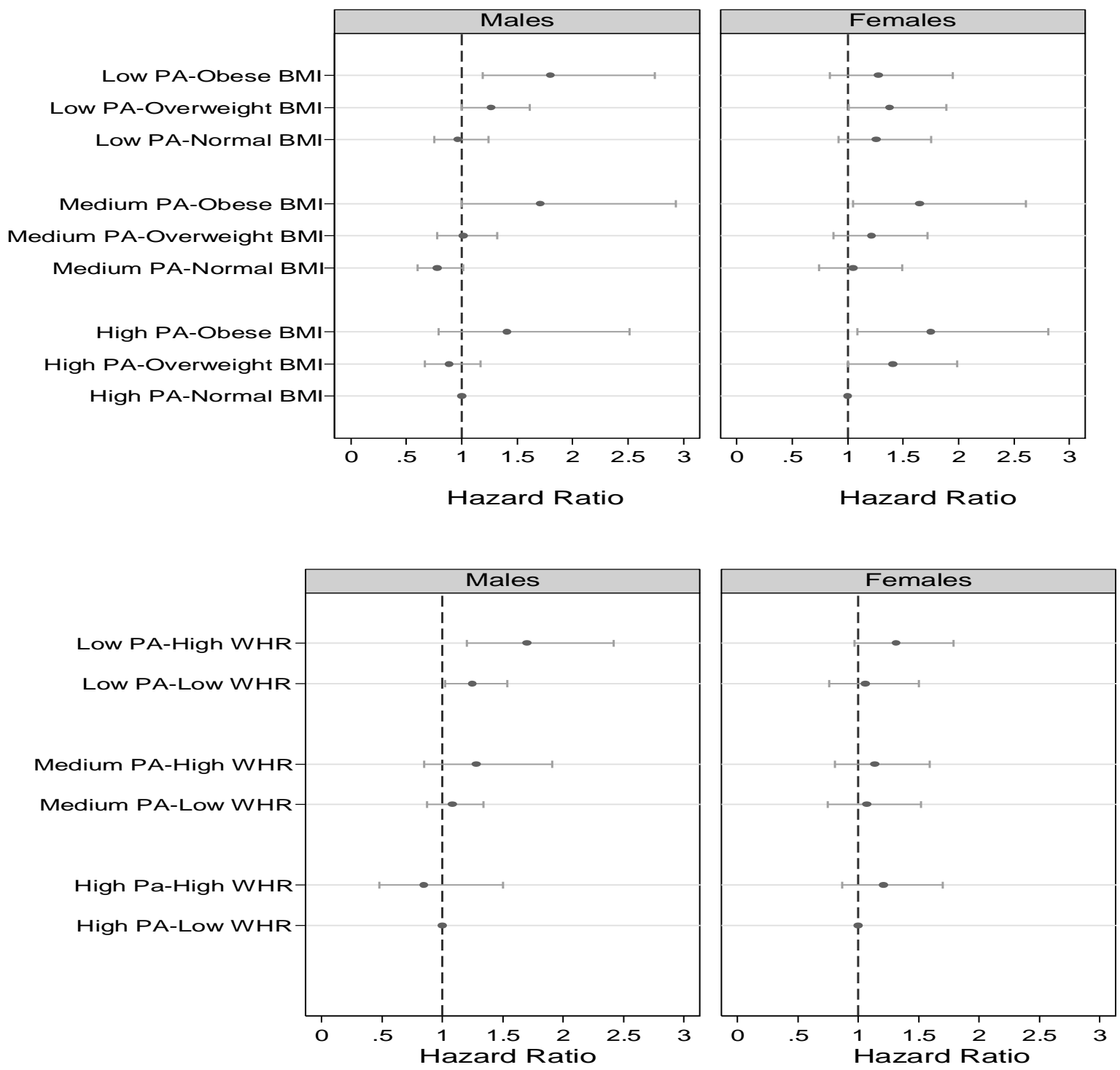

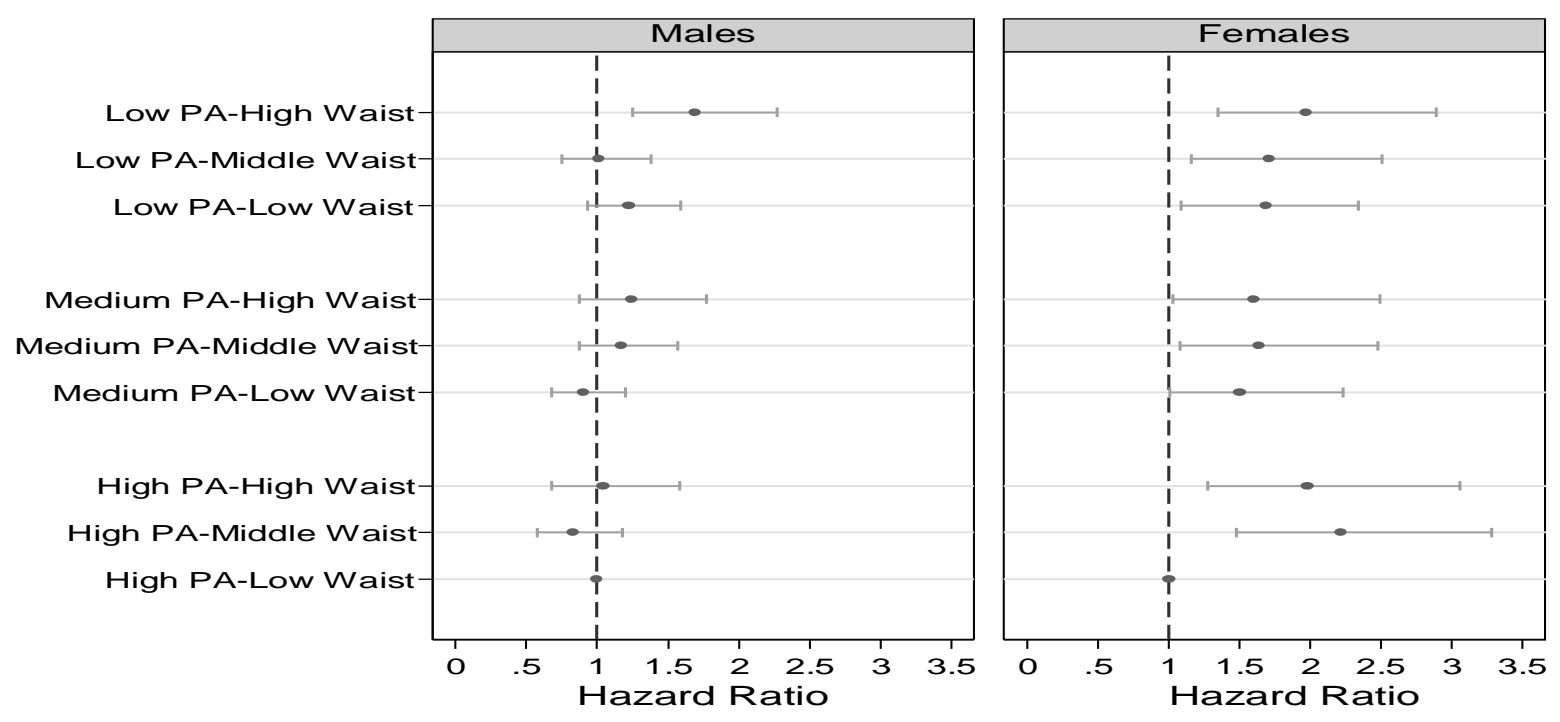
Figure 3

Males
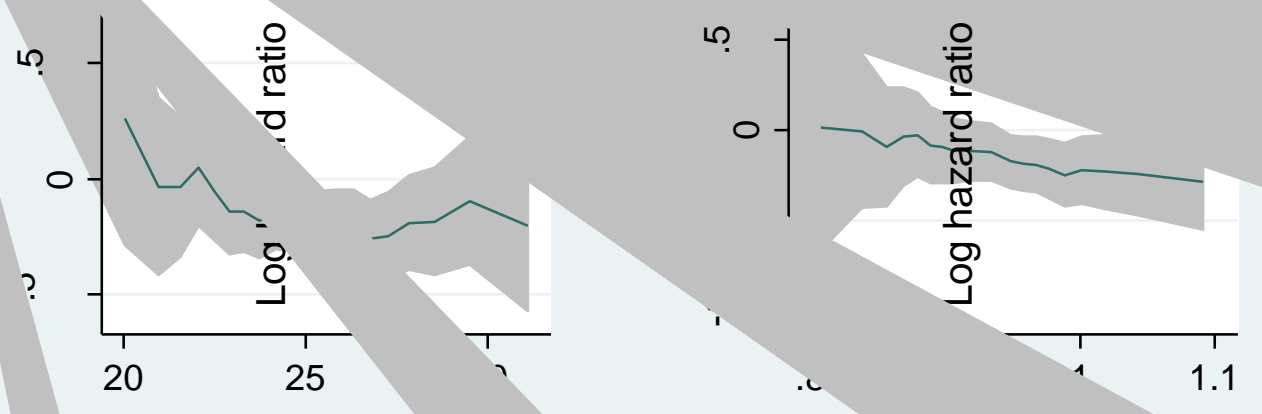

BMI

Females
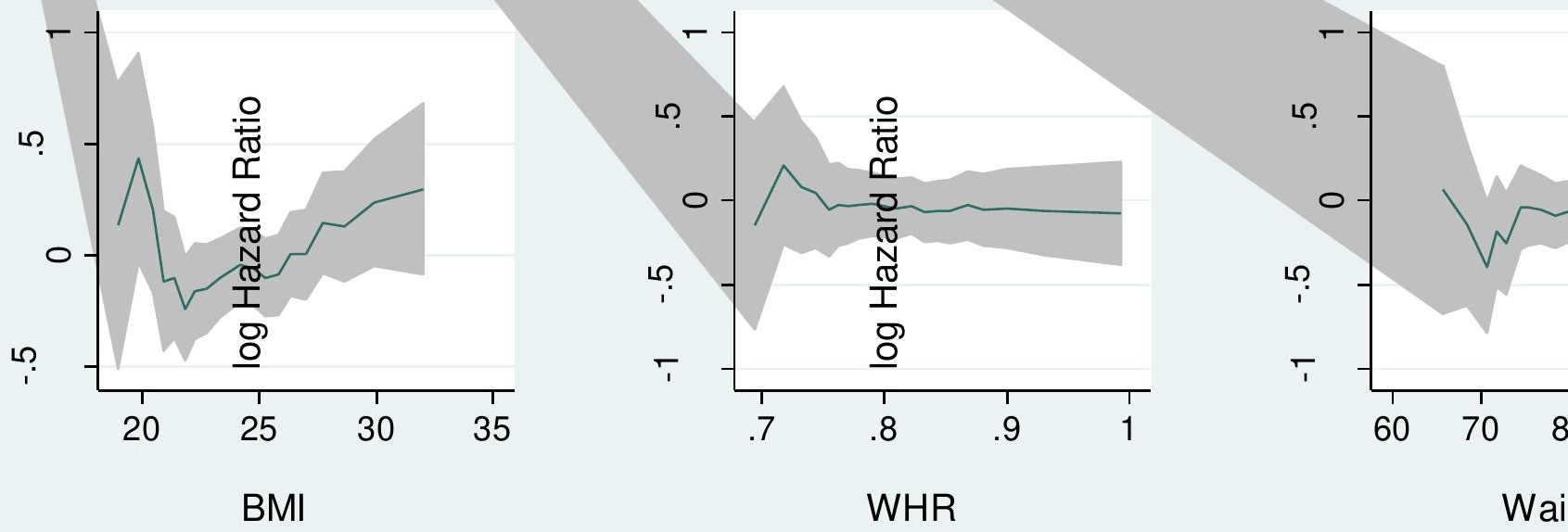